\title{
A DIVERSIDADE CULTURAL NAS FESTAS DE SÃO BENEDITO E NOSSA SENHORA DO ROSÁRIO NO SUL DE MINAS GERAIS ${ }^{1}$
}

Jhonatan da Silva Corrêa ${ }^{2}$

Flamarion Dutra Alves ${ }^{3}$

RESUMO: O presente artigo busca entender a diversidade das festividades ligadas ao sagrado e ao profano no Sul de Minas Gerais. Na abordagem foi dado um enfoque sobre a disparidade cultural existente nos municípios de Machado e Silvianópolis, duas festividades importantes para o cenário cultural sul mineiro. Cada cidade possui sua especificidade na região, onde uma atitude mais concêntrica e externalizada de Machado contribui para o desenvolvimento cultural investindo em seus ternos e expandindo sua influência cultural para as cidades circunvizinhas em suas festividades. Silvianópolis mais descentralizada e importadora, na consolidação de seus espaços sagrados e itinerários simbólicos agrupa um misto de manifestações em sua reatualização festiva, não deixando de contribuir com outras festividades, mas possui como especificidade a importação dos ternos de outros municípios para as manifestações culturais no tempo e espaço festivo. Para o desenvolvimento do trabalho foi essencial a realização de pesquisa bibliográfica e trabalhos de campo com observações e aplicações de entrevistas semi estruturadas com o objetivo de entender essa diversidade cultural ligada ao espaço sagrado nas festividades dos municípios estudados e sua importância e contribuição para o cenário cultural do Sul de Minas Gerais.

PALAVRAS-CHAVE: Religiosidade; Cultura; Tradição; Congada; Festa.

\section{CULTURAL DIVERSITY IN THE FEASTS OF SÃO BENEDITO AND NOSSA SENHORA DO ROSÁRIO IN THE SOUTH OF MINAS GERAIS}

\footnotetext{
${ }^{1}$ O presente trabalho foi realizado com apoio da Coordenação de Aperfeiçoamento de Pessoal de Nível Superior - Brasil (CAPES).

${ }^{2}$ Mestrando em Geografia pelo Programa de Pós-graduação em Geografia da UNIFAL-MG, bolsista Capes, integrante do Grupo de Estudos Regionais e Socioespaciais (GERES) da UNIFAL-MG e Núcleo de Estudos e Pesquisa Sobre Espaço e Cultura (NEPEC) em rede da UERJ, Brasil. E-mail: jhonatan.correa@sou.unifal-mg.edu.br

${ }^{3}$ Doutor em Geografia pela UNESP -Rio Claro e Professor Associado II do Programa de Pósgraduação em Geografia da UNIFAL-MG e Programa de Pós-graduação em Geografia da UFSJ, Líder Do Grupo de Estudos Regionais e Socioespaciais (GERES) da UNIFAL-MG, Brasil. E-mail: flamarion.dutra@unifal-mg.edu.br
} 
ABSTRACT: The present article seeks to understand the diversity of the festivities linked to the sacred and the profane in the South of Minas Gerais. The approach was focused on the cultural disparity existing in the municipalities of Machado and Silvianópolis, two important festivities for the cultural scene of southern Minas Gerais. Each city has its specificity in the region, where a more concentric and externalized attitude of Machado contributes to the cultural development investing in its suits and expanding its cultural influence to the surrounding cities in its festivities. Silvianópolis, more decentralized and importer, in the consolidation of its sacred spaces and symbolic itineraries, groups a mix of manifestations in its festive updating, not failing to contribute with other festivities, but has as specificity the importation of the ternos from other municipalities for the cultural manifestations in the festive time and space. For the development of the work it was essential to carry out bibliographic research and field work with observations and application of semi structured interviews with the objective of understanding this cultural diversity linked to the sacred space in the festivities of the municipalities studied and its importance and contribution to the cultural scene of southern Minas Gerais.

KEY WORDS: Religiosity; Culture; Tradition; Congada; Feast.

\section{DIVERSIDAD CULTURAL EN LAS FIESTAS DE SÃO BENEDITO Y NOSSA SENHORA DO ROSÁRIO EN EL SUR DE MINAS GERAIS}

RESUMEN: El presente artículo pretende comprender la diversidad de las fiestas vinculadas a lo sagrado y lo profano en el sur de Minas Gerais. En el planteamiento se dio un enfoque a la disparidad cultural existente en las ciudades de Machado y Silvianópolis, dos festividades importantes para el escenario cultural del sur de Minas Gerais. Cada ciudad posee su especificidad en la región, donde una actitud más concéntrica y externalizada de Machado contribuye para el desarrollo cultural invirtiendo en sus trajes y expandiendo su influencia cultural para las ciudades circundantes en sus festividades. Silvianópolis más descentralizada e importadora, en la consolidación de sus espacios sagrados e itinerarios simbólicos agrupa una mezcla de manifestaciones en su actualización festiva, no dejando de contribuir con otras festividades, pero posee como especificidad la importación de los ternos de otros municipios para las manifestaciones culturales en el tiempo y espacio festivo. Para el desarrollo del trabajo fue fundamental la realización de una investigación bibliográfica y un trabajo de campo con observaciones y aplicación de entrevistas semiestructuradas con el objetivo de comprender esta diversidad cultural vinculada al espacio sagrado en las fiestas de los municipios estudiados y su importancia y contribución al escenario cultural del Sur de Minas Gerais.

PALABRAS CLAVE: Religiosidad; Cultura; Tradición; Congada; Fiesta.

ReVISTA Eletrônica da Associação dos Geógrafos Brasileiros Seção Três Lagoas - v. 1, № 34 , 2021. 
INTRODUÇÃO

Para o desenvolvimento da pesquisa inicialmente duas festividades foram escolhidas sendo elas a Festa de São Benedito e a Festa de Nossa Senhora do Rosário, em Silvianópolis-MG, ambas possuem mais de um século de existência, sendo a primeira com 107 anos e a segunda com 2041. As formas de manifestação do sagrado estão inseridas no catolicismo popular brasileiro, isso implica em uma maior capacidade de lidar com as disparidades culturais e também de incorporar novos elementos religiosos em sua estrutura podendo advir de uma diversidade étnica. O importante é destacar que nesta prática religiosa pode haver reinterpretações diversas de rituais da Igreja Católica Apostólica Romana agregadas a outras simbologias e significados (SÜSS, 1979).

Os municípios de Machado e Silvianópolis estão localizados no Sul de Minas Gerais conforme mostra o Mapa 1. Machado possui uma população estimada para o ano de 2020 de 42.413 habitantes e Silvianópolis uma estimativa de 6.027 moradores para o mesmo ano (IBGE, 2020).

Mapa 1: Localização dos municípios de Machado e Silvianópolis. 


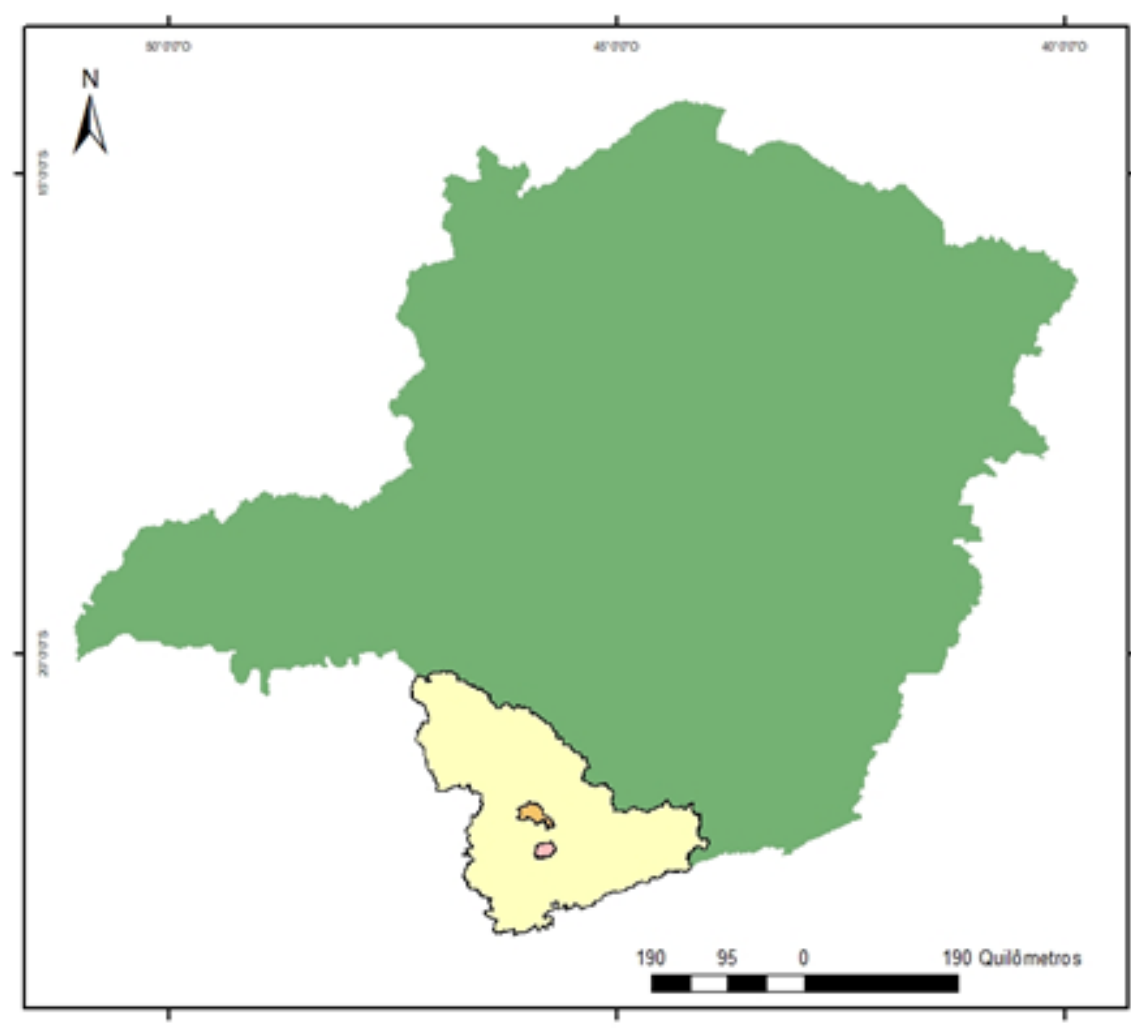

\section{Legenda}

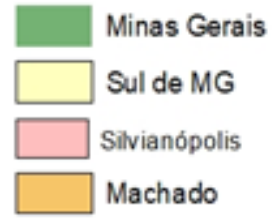

Projeção: UTM

DATUM: SIRGAS 2000

$\mathrm{F}: 23 \mathrm{~S}$

Fonte: IBGE

Fonte: CORRÊA (2021) organizado em outubro de 2021.

No Sul de Minas Gerais, conforme o último censo demográfico (IBGE, 2010)

há o predomínio do catolicismo entre a população da região, com 1.922.791 de religiosos, representando $78,85 \%$ da população total; os evangélicos possuem 25,44\% da população da região; esses dados perpassam a média nacional, que estavam em 64,6\% de católicos em 2010. O município de Machado possui por volta de $76 \%$ da população católica e $83 \%$ de seus habitantes são moradores urbanos. Os municípios pequenos possuem em sua população maior número de católicos, em Silvianópolis há cerca de $84 \%$ de seus habitantes, no entanto em outras localidades no Sul de Minas Gerais que possuem em sua população mais de 90\% católicos, sendo a realidade de 23 municípios da região.

A porcentagem da população católica acima de $80 \%$ é composta por pequenas cidades, com menos de 20 mil habitantes. Isso se deve muitas vezes às tradições familiares e locais que dificultam a aceitação de outras religiões e também às características do catolicismo no mundo rural. 
Contudo, apesar desse índice elevado do catolicismo, as manifestações religiosas se concretizam de diversas maneiras, incluindo em suas realidades, por exemplo, o catolicismo popular, aqui pesquisado, tem em sua manifestação rituais que em seu âmago há elementos de outras religiões.

Sendo assim, o catolicismo oficial, das estatísticas, convive com o catolicismo popular das práticas religiosas. O catolicismo popular traz em sua estrutura atrelado a questão religiosa uma criatividade, um mutualismo entre as culturas que de forma horizontal permite com mais eficácia e rapidez a troca entre o saber popular e sua prática religiosa (SÜS, 1978, p. 28).

A Festa de São Benedito, em Machado, desde a década de quarenta do século XX ocorre na segunda quinzena do mês de agosto, devido ao término da colheita do café, uma das principais fontes econômicas do município (GONÇALVES; REIS, 1979). O primeiro registro escrito da festividade foi realizado no ano de 1914, através da organização popular com destaque para a população preta (REBELLO, 2006). Com o decorrer do processo histórico a relação do catolicismo popular frente ao catolicismo oficial se deu de maneira conflitante, moldando toda condição espacial referente à Festa de São Benedito, fundando territórios e territorialidades que perpassam a religião e constituem novos usos não somente durante os dias festivos (CORRÊA, 2019; CORRÊA; ALVES, 2020).

Em relação à Festa de Nossa Senhora do Rosário, em Silvianópolis, destacamos que sua gênese ocorreu por volta do ano de 1780, no dia 13 de junho. A priori, tratou-se uma festa introduzida por um padre com a finalidade de catequizar os escravizados ali situados. No perpassar de mais de dois séculos dessa manifestação cultural, a organização festiva não deixou de ter seus conflitos entre as vertentes do catolicismo popular e oficial, sendo perceptível um forte domínio pretendido pela Igreja Católica Apostólica Romana sobre a constituição festiva (DOMINGUES, 2017; DUTRA, 2006). 
As festividades possuem muito em comum, no entanto, através do seu lugar e desenvolvimento histórico construíram especificidades em suas estruturas, fazendo as práticas existentes nas estruturações festivas diversas e únicas. Ademais, falar de religião nunca é falar circunscritamente a ela, mas também é levar em considerações as questões políticas, econômicas e culturais que permeiam suas manifestações (ROSENDAHL, 2018). Portanto, ao compreender as maneiras de constituição das festividades, pode mostrar muito sobre as estratégias traçadas por populares nos municípios para a manutenção cultural Sul mineira.

\section{MATERIAIS E MÉTODOS}

Inicialmente foi realizada uma revisão bibliográfica por meio de diferentes fontes com o intuito de buscar compreender mais a respeito da história das festividades e como elas surgiram; um estudo de gabinete. Para tanto, houve a necessidade de consultar a Associação de Caridade Nossa Senhora do Rosário, em Silvianópolis, e a Associação dos Congadeiros Tio Chico, em Machado, Prefeitura Municipal de Machado e Casa da Cultura. Além do mais, juntamente às questões festivas, houve também uma revisão sobre os conceitos trabalhados sendo eles: o espaço sagrado e profano, território, territorialidade, poder e lugar.

Na segunda parte da metodologia foram realizados trabalhos de campo, a pesquisa apresentada é fruto de duas iniciações científicas, uma monografia e uma dissertação em andamento. Portanto, os trabalhos de campo aconteceram nos anos de 2016, 2017, 2018, 2019, 2020 e 2021, buscando analisar as festividades e suas dinâmicas referentes ao lugar, a política e o econômico (ROSENDAHL, 2003). Ademais, cabe ressaltar que os trabalhos de campo exercem grande importância, devido a necessidade de o pesquisador estar presente nas manifestações estudadas: 
A pesquisa de campo deve ser incentivada como instrumento metodológico, pois permite ao pesquisador uma maneira privilegiada de obtenção de dados etnográficos confiáveis da religiosidade do crente em suas manifestações na paisagem religiosa e no lugar sagrado (ROSENDAHL, 2012, p. 27).

Nos trabalhos de campo as observações foram essenciais para compreender as dinâmicas festivas e, assim, perceber suas disparidades. Através dessas diferenças elementos são isolados e compreendidos conforme destacado: "Observar significa selecionar, classificar, isolar, com base na teoria" (MALINOWSKI, 1975, p. 21). Além das observações para entender o espaço e o tempo festivo, as entrevistas semiestruturadas foram realizadas com participantes das festividades ligados diretamente ou indiretamente à organização festiva. A maneira de entrevistar nos últimos anos, mais precisamente em 2020 e em 2021 sofreu alterações com a ocorrência da pandemia, assim como as estratégias de reatualização das festividades, dando grande destaque às mídias sociais e aos Itinerários Simbólicos (CORRÊA, 2020b).

Utilizar entrevistas semiestruturadas proporciona um ambiente dinâmico, possibilitando que novos assuntos e até mesmo novas direções sejam traçadas no percurso de sua aplicação. Ao elaborar as questões, no trabalho de campo, novas discussões foram emergindo. "O entrevistador segue um determinado número de questões principais e específicas, em uma ordem prevista, mas é livre para incluir outras questões" (LIMA, 2006, p. 27).

A vivência, a geograficidade e o ser histórico são levados em consideração no desenvolver da pesquisa. Segundo Holzer (2010), a ontologia contemporânea traz para a discussão o mundo que construímos e a representação do ser pautadas nas divergências existenciais. Trabalhar com a geografia das existências é buscar entender o lado que não possui voz, é compreender o indivíduo em sua coletividade e singularidade (SILVA, 2014). Por isso, fazer uma geografia decolonial é falar dos símbolos e práticas do catolicismo popular e não oficial, dos rituais 
desprovidos da hierocracia presentes na Igreja Apostólica Romana e das festas dos santos populares que resistem e existem há séculos no Sul de Minas Gerais.

\section{RESULTADOS E DISCUSSÕES}

O espaço sagrado e profano é de grande importância para pesquisa, pois é através dele que a Geografia consegue fazer as interpretações da religião (ROSENDAHL, 2012). Em consonância com a geógrafa Rosendahl (1999), o sagrado consiste na experiência regida e guiada pelo simbolismo religioso, já o espaço profano seria desprovido de sacralidade. Ademais: "O sagrado e o profano se opõem e, ao mesmo tempo, se atraem. Jamais, porém, se misturam" (ROSENDAHL, 2002, p. 31).

Esse dualismo entre espaço sagrado e profano acontece nas festividades populares ligadas ao catolicismo popular onde através de um ritual de inicialização festiva, como a subida do mastro há o que Claval (2014) chamou de inversão social e catarse, onde o tempo e o espaço passam a ser entendidos tanto em suas abordagens cronológica como kairológica, dependendo do momento vivenciado (ROSENDAHL, 2018). "Por meio da habilidade humana, a natureza é transformada em objetos culturais. [..] As representações de mundo são construídas na produção desses objetos culturais que, reunidos no tempo e no espaço, transformam a paisagem em lugar" (LUCHIARI, 2001, p. 22).

Para compreender o lugar é necessário entendê-lo como um espaço estruturado por significações, sendo assim, para sua constituição a pausa é necessária; servindo o movimento para o espaço destituído de vínculo e significado (TUAN, 2013). Segundo Dardel (2015), o homem tem como sua realidade geográfica o lugar no qual se encontra e constitui elementos basilares de sua vida como o bairro onde passou a infância, o lugar onde ele mora, trabalha e referentes aos costumes diários. Por isso, para formulação do lugar a carga 
simbólica é importante, podendo ser bom para alguns e ruim para outros (SOUZA, 2015).

Prossigamos, discutir o território e seus derivados é muito importante para o desenvolvimento da pesquisa. Para Haesbaert (2006), o território não está associado somente aos aspectos físicos, mas também às questões ligadas às identidades sociais. O geógrafo Bonnemaison (2002) destaca que não existe grupo cultural ou etnia que no ato da sua existência não tenha de alguma forma direta ou indireta investido na formação de seu território físico e cultural. Logo, podemos destacar o território como um importante meio para garantir a sobrevivência física e cultural de seu criador, havendo elementos que reforçam os aspectos políticos, étnicos, religiosos, entre outros (ROSENDAHL, 2013).

Para mais, Raffestin (1993) revela que o território se produz através das relações de poder, é um local onde se teve a projeção do trabalho da energia e informação. A produção, troca e consumo que existe no território é o que produz a territorialidade. Sendo assim, em nossas relações sociais as territorialidades são reforçadas através de diversos aspectos sendo o religioso um deles, e traz em sua constituição a relação com o poder (SAQUET, 2015).

Para mais, há na territorialidade continuidade e descontinuidades situadas no tempo e no espaço. As territorialidades possuem um elo com o lugar, estabelecendo sua identidade e constituindo parâmetros perante sua condição ligada à história e à geografia de cada lugar (SAQUET, 2015b). Por esse motivo, as práticas religiosas desenvolvidas em um determinado tempo e espaço por uma instituição ou grupo buscam em sua realização o controle de um determinado território, o sagrado exerce um poder que configura o sentido de domínio. Nesse território, toda troca existente entre os religiosos de forma plural ou singular, nos itinerários sagrados ou no lugar configura uma territorialidade (ROSENDAHL, 2013). 
É perceptível que tanto no território como na territorialidade o poder se faz presente. O poder deve, em sua análise, ser compreendido como algo que circula, funcionando em rede. As pessoas podem através de sua ação praticar poder em um momento e em outro sofrer suas consequências, não sendo estático e nem podendo detê-lo no processo - mas sim ser um centro de transmissão (FOUCAULT, 2017, p. 274). Por esse motivo, o poder está presente em toda camada social, desde a microestrutura até a macroestrutura. Para mais, a ação do poder estabelece de forma perpetuada o conhecimento, resultando em mais poder hegemônico. Toda essa estrutura se constitui através de um processo histórico.

\section{AS ORGANIZAÇÕES FESTIVAS E SUAS ESTRUTURAS}

Tanto a Festa de São Benedito como a de Nossa Senhora do Rosário possuem como padroeiros três santos, sendo eles: Nossa Senhora do Rosário, Santa Efigênia e São Benedito. Contudo, nas duas comemorações festivas há presença do sincretismo religioso, onde elementos de outras religiões são incorporados aos ternos. Essa ocorrência manifesta-se de diferentes formas, dependendo do terno de Congo, Moçambique ou Caiapó. As bases presentes nas manifestações podem ser entendidas como referentes aos portugueses, às religiões de matrizes africanas, e indígenas, aculturadas durante o espaço e o tempo (AZEVEDO, 2002).

Em Machado, a organização festiva é realizada por meio de um tripé, sendo a Prefeitura municipal de Machado, Paróquia Santo Antônio e Sagrada Família e Associação dos Cangaceiros Tio Chico (CORRÊA; ALVES, 2017). Essa estrutura é recente e a Associação dos Congadeiros criada em 1982 tem a função de representar politicamente os ternos de Congadas e Caiapó do município, defendendo seus interesses (REBELLO, 2006). Ação necessária principalmente 
devido ao processo de mercantilização festiva, pois, a população progenitora da festividade viu sua dimensão territorial diminuir no decorrer dos anos no município (CORRÊA, 2020a; CORRÊA; ALVES, 2020).

Para mais, há 18 ternos de Congadas e 1 grupo de Caiapó em Machado e durante o espaço e tempo festivo são eles que possuem a incumbência de instituir a reatualização festiva e sua ruptura no espaço e tempo. Além do mais, Machado possui grande importância no cenário cultural do Sul de Minas, onde suas Congadas participam com assiduidade de outras festividades, levando as características autóctones para outras territorialidades, conforme mostram as Figuras $1 \mathrm{a}$ e $1 \mathrm{~b}$.

Figuras 1a e 1b: Ternos de Machado em outros municípios
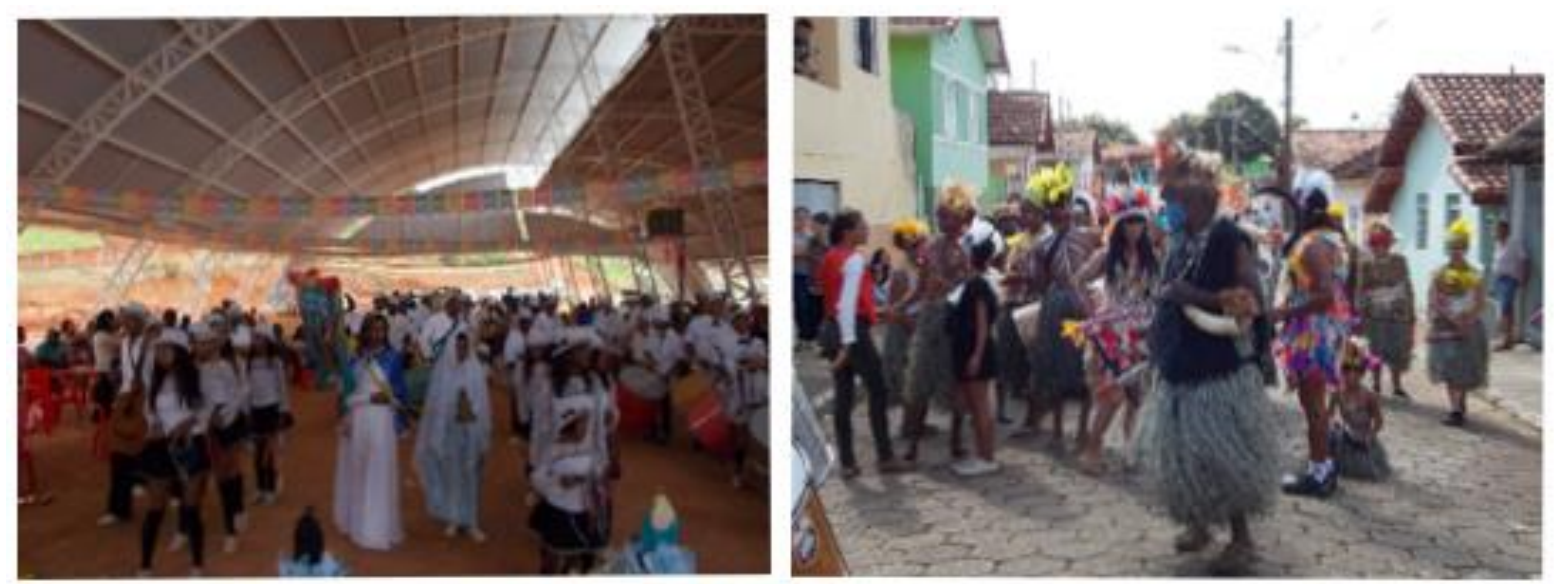

Fonte: CORRÊA (2021) - trabalhos de campos em 2018 e 2019.

Nas Figuras 1a e 1b é possível analisar um terno de congada de Machado fazendo uma apresentação em Carvalhópolis no ano de 2018 no encontro de congadas do município e o grupo dos Caiapós se apresentando na Festa de Nossa Senhora do Rosário em Silvianópolis no ano de 2019. É compreensível a importância do município para o desenvolvimento cultural no Sul de Minas Gerais no que tange às festividades populares religiosas. 
Em Silvianópolis, apesar da festividade ser implantada pelo catolicismo oficial, com o tempo e alguns acontecimentos, a organização festiva desvencilhouse da estrutura clerical e adentrou em uma constituição deveras popular, sendo assim até o presente momento (DOMINGUES, 2017). O motivo dessa ruptura foi ocasionado devido a contenda advinda entre a Irmandade dos homens pretos de Silvianópolis e a Igreja Católica Apostólica Romana (DUTRA, 2006). Hodiernamente, a principal organizadora da festividade é a Associação de Caridade Nossa Senhora do Rosário, antiga Irmandade dos Homens Pretos, inclusive, diferentemente de Machado, a atual Capela de Nossa Senhora do Rosário é cuidada pela instituição sem a presença de membros eclesiásticos.

Contudo, Silvianópolis não possui uma associação que defenda os interesses políticos dos congadeiros, havendo dois ternos de congadas no município. Além do mais, no espaço e tempo festivo há grande diversidade de manifestações advindas de outros locais conforme mostram as Figuras $2 a$ e 2b, chegando a ter de 20 a 30 ternos de Congada, Moçambique e Caiapós enriquecendo a festividade.

Figuras 2a e 2b: Diversidade de ternos de outros municípios em Silvianópolis
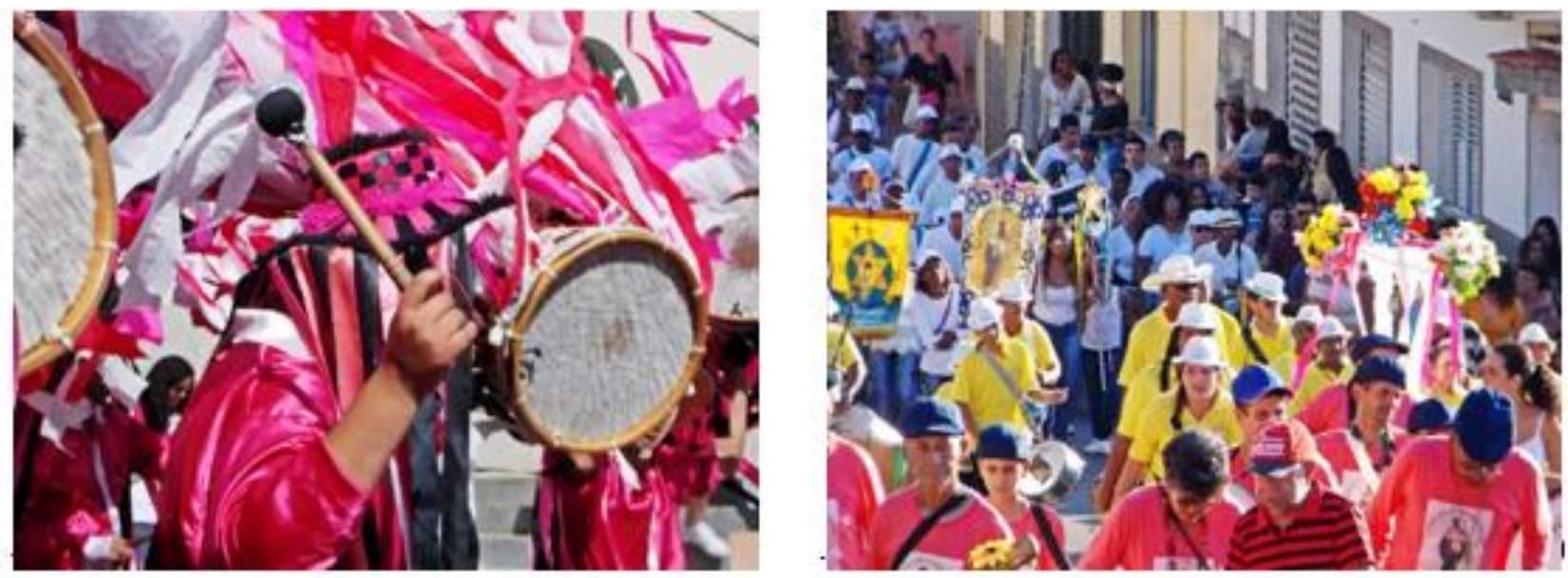

Fonte: CORRÊA (2021) - trabalhos de campo, 2018 e 2019 
Nas Figuras 2a e 2b é perceptível a diversidade das manifestações culturais presentes no município durante a festa. Os ternos e grupos advindos de diversas localidades possuem grande variabilidade sonora, de vestimentas e rituais, trazendo enorme contribuição para o cenário cultural da região. Ademais, cabe ressaltar que os ternos de Silvianópolis também viajam para outras festas. Estruturalmente, as festas possuem momentos parecidos sendo o marco inicial o levantamento do mastro instituindo a temporalidade e espacialidade das manifestações.

Devido a Festa de São Benedito ser registrada, os ternos de congadas possuem ajuda financeira do município, o que possibilita uma melhor estruturação. Em Silvianópolis, os ternos se mantêm com mais dificuldade, há pouca contribuição dos órgãos públicos. Porém, a festividade ganha na independência organizacional popular, podendo ser administrada livremente as "esmolas" recebidas para sua materialização por intermédio dos festeiros.

Estrategicamente existe em Machado o desejo de fortalecer seus ternos, então dificilmente há congadas de outros locais na Festa de São Benedito, o que não impede dançantes de outras áreas adentrarem os ternos. Sonoramente e visualmente, em Silvianópolis existe maior disparidade entre os ternos havendo: Moçambique, Caiapó e as Congadas. Em Machado não há Moçambique nos itinerários simbólicos.

\section{A DIVERSIDADE CULTURAL DO SAGRADO}

Em Machado, ao buscar entender como a Festa é estrutura sendo ela pela Prefeitura Municipal, Associação dos Congadeiros Tio Chico e Paróquia Santo Antônio e Sagrada Família, há em sua estrutura um amparo maior ao cenário cultural vindo do poder público, podendo ter variações de acordo com a administração vigente. No entanto, pela festa ser tombada como Patrimônio 
Imaterial do povo machadense já garante uma manutenção do poder público perante as manifestações culturais ligadas à festa.

Os ternos de Congadas e o grupo de Caiapó de Machado possuem o hábito de participar de outras festividades circunvizinhas ao município. Sendo assim, devido aos 18 ternos de Congo e 1 grupo de caiapó, possui influência e ajuda na consolidação do espaço sagrado e nos itinerários simbólicos de outros localidades - principalmente das cidades pequenas mais próximas onde exerce uma certa influência sendo caracterizada como uma subcentralidade B de Alfenas e uma cidade intermediária (IBGE, 2008; ANDRADE, 2015). De certa forma, essa centralidade e característica intermediária de Machado possibilita uma maior estruturação do cenário cultural, possuindo mais ternos e mais recursos para a manutenção cultural do município, o que não garante sua valorização e autossuficiência. Contudo, coloca a cidade como um centro de dispersão regional da cultura do Congo.

Já a Festa de Nossa Senhora do Rosário possui grande diversidade de ternos em sua composição, chegando em seus momentos de grandes hierofanias conter entre 15 a 30 ternos e grupos se apresentando, desses apenas dois são do município. Silvianópolis é uma cidade pequena e possui em sua festividade uma heterogeneidade sonora e visual, justamente pelos ternos presentes pertencerem a diversas localidades, culminando em uma festa mais pluralista em seus ritmos, vestimentas e rituais. Consequentemente, uma manifestação que tem o seu espaço festivo diverso com ternos de congadas de diferentes partes do Sul de Minas Gerais, do estado de Minas Gerais e até mesmo de outras unidades federativas. Além do mais, essa riqueza festiva nos faz compreender a festa como um centro de conversão da cultura de Congada no Sul de Minas Gerais.

Essa diversidade sonora, rítmica e de vestimenta é o que caracteriza a festividade e faz dela muito importante para a manutenção cultural da região. Além do mais, devido a carências na área de serviços do município, virou tradição 
o almoço e o café da manhã servido no barracão dos congadeiros, justamente pela cidade não possuir uma rede de restaurantes que dê conta da demanda nos dias festivos. O almoço no barracão já é uma tradição, junto com o doce que também é servido e não fica restrito somente aos ternos de Congadas, Moçambiques e Caiapós, a população também comparece sendo esse um momento muito esperado.

Em Machado os ternos são do município, os almoços coletivos não acontecem em um mesmo local, mas sim em terreiros ou ranchamento dos ternos da cidade onde cada capitão alimenta os integrantes do seu terno. Esses almoços podem ser abertos para a população mais próxima, não sendo tão abrangente como o existente em Silvianópolis.

Portanto, ambas festividades possuem grande importância para o desenvolvimento cultural do Sul de Minas Gerais. As contribuições são diferentes e caminham juntas para salvaguardar a cultura local de diversas formas de apropriações existentes ao longo do espaço e do tempo festivo, um grito de resistência e reatualização das práticas culturais populares.

\section{CONSIDERAÇÔES FINAIS}

Falar sobre o catolicismo popular é dar visibilidade para aqueles que nunca tiveram os holofotes sobre seus modos de vida, experiências e organizações. Trabalhar o indivíduo singular e plural, sua geograficidade e sua vivência mostra o quanto a geografia pode contribuir para o esfacelamento da desigualdade entre os diferentes. Trabalhar existências é dar um grito de liberdade, é mostrar que há luta e resistência para que as reatualizações se concretizem. Falar de catolicismo popular é falar de economia, cultura, território e também do catolicismo oficial, mas sem deixar de lado aqueles que mais enriquecem nossa cultura, o povo 
mineiro muitas vezes esquecidos por uma geografia voltada às grandes instituições.

Portanto, as festividades de acordo com o seu lugar têm especificidades. Essas características conduzem as diferenciações que cumprem papel essencial na manutenção cultural regional. Não existe uma festa melhor que a outra; o que temos são contribuições díspares que enriquecem a forma estrutural onde algumas festas cumprem funções diferentes. Contudo, são essenciais para a longevidade e perpetuação da diversidade e formação cultural.

Logo, ao entender as maneiras como se comportam as festividades e suas estruturas se torna facilmente analisável e compreensível o papel de cada uma no Sul de Minas Gerais. Consequentemente, mostrando suas tradições, aspectos próprios que buscam em sua reatualização elementos que sustentem suas dinâmicas e contribuam para salvaguardar as características do lugar atreladas às da região. Sendo assim, festas que de longe parecem iguais; mas que de perto demonstram suas especificidades e importância para o cenário cultural do Sul de Minas Gerais.

\section{REFERÊNCIAS BIBLIOGRÁFICAS}

ANDRADE, A. C. As Cidades Médias e Suas Inserções nos Espaços Regionais: o contexto do sul de Minas Gerais. Revista Territorium Terram, v.3, n.5, p. 64-79, jan/jun, 2015.

AZEVEDO, T. O Catolicismo no Brasil: um campo para a pesquisa social. Salvador: Edufba, 2002.

BONNEMAISON, J. Viagem em Torno do Território. In: CORRÊA, R. L.; ROSENDAHL, Z. (org). Geografia Cultural: um século (3). - Rio de Janeiro: EdUERJ, 2002.

CLAVAL, P. A Geografia Cultural. Tradução: Luís Fugazzola, Margareth de Castro Afeche Pimenta. -4. Ed. rev. - Florianópolis: Ed. da UFSC, 2014. 
CORRÊA, J. S.; ALVES, F. D. A Questão Territorial da Festa de São Benedito em Machado-MG. Geographia Opportuno Tempore, Londrina, v.3, n. 2, p. 165-178, 2017.

CORRÊA, J. S.; ALVES, F. D. Festa de São Benedito: territorialidade e a manifestação do circuito inferior em Machado-MG. Revista GeoNordeste, São Cristovão, Ano XXXI (2020), n.1, p.40-53. Jan/Jun. .Disponível em: https://seer.ufs.br/index.php/geonordeste/article/view/11841. Acesso em 15 de Março de 2021. https://doi.org/10.33360/RGN.2318-2695.2020.i1.p.40-53

CORRÊA, J. S. Festa de São Benedito: territorialidade e cultura no município de Machado-MG. In: PIMENTA, C. A. M.; LOPES, R. J. (org). Panoramas das Políticas Culturais e Ambientais no Brasil. 1 e.d - Porto Alegre: Cirkula, 2016 - 2020a. V3.

CORRÊA, J. S. Festas Silenciosas: formas de cultuar perante à pandemia. In: Anais do $4^{\circ}$ Workshop de Geografia Cultural: Territorialidades do Sagrado: abordagens da geografia da religião. Unifal-MG, 2020b. Disponível em: https://www.unifalmg.edu.br/geografia/sites/default/files/1_21jhonatan.pdf. Acesso em 20 de março de 2021. https://doi.org/10.13140/RG.2.2.13806.64323.

CORRÊA, J. S. Religião e Poder: a romanização no Sul/Sudoeste de Minas Gerais. Geographia Opportuno Tempore, Londrina, v.5, n.2, p. 104-121, 2019.

DARDEL, E. O Homem e a Terra: natureza da realidade geográfica. tradução Werther Holzer. - São Paulo: Perspectiva, 2015.

DOMINGUES, A. S. Cultura e Memória na Festa de Nossa Senhora do Rosário na cidade de Silvianópolis-MG. Pouso Alegre. Univás, 2017.

DUTRA, C. M. Sant'Ana do Sapucaí atual Silvianópolis. Ed. Amaral, Pouso AlegreMG. 2006.

FOUCAULT, M. Microfísica do Poder. Organização, introdução e revisão técnica de Roberto Machado. - 6 ed. - Rio de Janeiro/ São Paulo: Paz e Terra, 2017. 
GONÇALVES, C. C.; REIS, M. S. A Festa de São Benedito em Machado. Machado MG. 1979.

HAESBAERT, R. Territórios Alternativos/ Rogério Haesbaert. Editora Universidade Federal Fluminense. Rio de Janeiro - RJ, 2006.

HOLZER, W. Método Fenomenológico: humanismo e a construção de uma Nova Geografia. In: ROSENDAHL, Z.; CORRÊA, R. L. (orgs.). Temas e Caminhos da Geografia Cultural. - Rio de Janeiro: EdUERJ, 2010.

IBGE - Instituto Brasileiro de Geografia e Estatística. Cidades. [on line]. Disponível em: https://cidades.ibge.gov.br/brasil/mg/machado/panorama. Acesso em: 07 de abril de 2021.

IBGE - Instituto Brasileiro de Geografia Estatística. Censo Demográfico. 2010. Disponível em: https://sidra.ibge.gov.br/pesquisa/censodemografico/demografico-2010/inicial. Acesso em: 20 de dezembro de 2020.

IBGE - Instituto Brasileiro de Geografia Estatística. Regiões de Influencias das Cidades 2007 - REGIC. Rio de janeiro: IBGE, 2008.

LIMA, M. Uso da Entrevista na Pesquisa Empírica. In: ABDAL, A, Et al. Métodos de Pesquisa Sociais: Bloco Qualitativo. Sesc São Paulo/ CEBRAP. São Paulo 2016.

LUCHIARI, M. T. D. P. A (Re)Significação da Paisagem no Período Contemporâneo/ In: ROSENDAHL, Z.; CORRÊA, R. L. (org). Paisagem, Imaginário e Espaço. Rio de Janeiro: EdUERJ, 2001. 228 p.

MALINOWSKI, B. Uma Teoria Científica da Cultura. Zahar Editores, Rio de Janeiro, 1975.

RAFFESTIN, C. Por Uma Geografia do Poder. Ed. Ática S.A, 1993.

REBELLO, R. M. Machado até a virada do milênio. - Machado - MG. Tomo II: 170193. 2006. 
ROSENDAHL, Z.; CORRÊA, R. L. Manifestações da Cultura no Espaço. Ed. Uerj, 1999. ROSENDAHL, Z. Espaço Cultura e Religião: Dimensão de Análise. In: CORRÊA. R, L.; ROSENDAHL, Z (org). Introdução a Geografia Cultural. - Rio de Janeiro: Betrand Brasil, 2003.

ROSENDAHL, Z. Espaço e religião: uma abordagem geográfica. - $2^{\circ}$ edição - Ed Uerj, Rio de Janeiro 2002.

ROSENDAHL, Z. História, Teoria e Método em geografia da Religião. Espaço e Cultura, UERJ, RJ, N. 31, p. 24-39, JAN./ JUN DE 2012

ROSENDAHL, Z. Território e Territorialidade: uma proposta geográfica para o estudo da religião. In: CORRÊA. R, L; ROSENDAHL. Z. (orgs.). Geografia Cultural: uma antologia, volume II. Rio de Janeiro: EdUERJ, 2013.

ROSENDAHL, Z. Uma Procissão na Geografia. Uma Procissão na Geografia. - Rio de Janeiro: EdUERJ, 2018.

SAQUET, M. A. As Territorialidades e as Temporalidades. In: SAQUET, M, A. Por Uma Geografia das Territorialidades e das Temporalidades: uma concepção dimensional voltada para a cooperação e para o desenvolvimento territorial. Ed. - Rio de Janeiro: Consequência, 2015(a).

SAQUET, M. A. Por uma Abordagem Territorial. In: SAQUET, M, L. SPOSITO, E, S. (orgs.). Territórios e Territorialidades: teorias, processos e conflitos. 2.Ed. - Rio de Janeiro: Consequência Editora, 2015(b).

SOUZA, M. L. Os Conceitos Fundamentais da pesquisa Sócio-espacial. - $2^{\circ}$ ed. Rio de Janeiro: Bertrand Brasil, 2015.

SÜSS, G. P. Catolicismo Popular no Brasil: tipologias e estratégias de uma religiosidade vivida. Ed. Loyola, São Paulo. 1978. 
TUAN, Y. Espaço e Lugar: A perspectiva a experiência. Tradução: Lívia de Oliveira. - Londrina: Eduel, 2013. 